\title{
Chapter 7: Emerging approaches in the analysis of inks on questioned documents
}

${ }^{1}$ Weyermann Céline*, ${ }^{1,2}$ Techabowornkiat Korn-usa

${ }^{1}$ Ecole des Sciences Criminelles, University of Lausanne, CH-1015 Lausanne, Switzerland.

*celine.weyermann@unil.ch

${ }^{2}$ Office of Forensic Science, Royal Thai Police Headquarters, Pathumwan, Bangkok 10330, Thailand. 


\title{
Chapter 11: Emerging approaches in the analysis of inks on questioned documents
}

Weyermann Céline, Techabowornkiat Korn-usa, 2019/10/01. dans In: Francese S. (eds) Emerging Technologies for the Analysis of Forensic Traces. Advanced Sciences and Technologies for Security Applications, Springer, Cham.

\section{Acknowledgements}

The authors wish to thank Dr. Raymond Marquis from the School of Criminal Justice of the University of Lausanne for the HPTLC results shown in Figure 7.1, Prof. Patrick Buzzini from the Department of Forensic Science of Sam Houston State University (Houston, Texas) for providing the Raman data illustrated in Figure 7.4, Dr. Matteo Gallidabino from the Department of Applied Sciences of Northumbria University for the acquisition of the LDI-MS data represented in Figure 7.5; Florentin Coppey from the School of Criminal Justice of the University of Lausanne for the production of the hyperspectral imaging for Figure 7.6, and Prof. Medhi Moini and his team from the Department of Forensic Sciences of the George Washington University for the DART and DSA-MS spectra represented Figure 7.7.

\begin{abstract}
Questioned document is one of the oldest fields of examination reported in forensic science. Documents are used as physical (nowadays sometimes virtual) traces of human transactions, thus questioning, falsification and counterfeiting certainly have existed since their invention and routine use. This is also the case for biblical texts and art pieces for which authenticity and authorship are often disputed. While mainly handwriting comparison was reported in early works, the composition and characteristics of inks on paper were often briefly discussed (see for example the early works of Demelle or Raveneau in the XVII ${ }^{e}$ century ${ }^{1}$ ). Since then, many technological developments have impacted questioned document examination, both with regard to the ink and paper production, as well as to the writing instruments or printing techniques. Nowadays, further progress have changed the world of (questioned) documents, through the introduction of virtual documents using electronic signatures $^{2}$ and security documents such as passports using mixed physical and digital biometric data. Thus, the document examiner' expertise has to quickly evolve and adapt to such developments, sometimes necessitating the combination of skills from different disciplines not always co-existing in forensic laboratories (such as chemistry, physics, statistics, engineering, material science, computer science). After a brief overview of the historical development in both ink formulation and analysis, this chapter will investigate the relevance of rapidly evolving technologies for application to the examination of questioned documents in a forensic perspective.
\end{abstract}

1 The scanned integral text of these books can be found on internet.

2 The European Commission defines the electronic signatures as follows: "An electronic signature is an electronic indication of a person's intent to agree to the content of a document or a set of data to which the signature relates. Like its handwritten counterpart in the offline world, an electronic signature is a legal concept capturing the signatory's intent to be bound by the terms of the signed document." https://ec.europa.eu/cefdigital// last access 16 of October 2018. 
Chapter 11: Emerging approaches in the analysis of inks on questioned documents

Weyermann Céline, Techabowornkiat Korn-usa, 2019/10/01. dans In: Francese S. (eds) Emerging Technologies for the Analysis of Forensic Traces. Advanced Sciences and Technologies for Security Applications, Springer, Cham.

\subsection{Introduction}

It is not possible to date the first human writings, but archaeological discoveries indicate that many different substances and instruments were widely used to write or carve inscriptions and drawings on different substrates such as stones walls. For example, in the Lascaux caves, metal oxides were used to produce the famous coloured paintings [1]. Later, writing inks used on papyrus and parchment were composed of carbonaceous compounds extracted from cephalopoda (e.g. squids) or carbonized organic substances [2]. Since the early XII ${ }^{\mathrm{e}}$ century, iron gall based inks have been widely used [3,4]. At the time, the ink composition did not vary much (chemically and visually) and it was erasable only through scraping. Such inks were used well into the $\mathrm{XX}^{\mathrm{e}}$ century [5]. Then, ink formulation evolved quickly to a variety of mixtures and properties, largely dependent on the development of different kind of writing and printing techniques. Thus, many ink compositions are available on the market and might differ significantly depending on the type of writing instrument (e.g. fountain, felt tip, roller ball or gel pens) or printer used (e.g. inkjet, toner or security printers). Inks are mainly composed of the following ingredients with some exceptions (e.g. toner printers do not require a solvent) [6,7]:

- dyes and/or pigments (to colour the ink),

- vehicles (to solubilise the dye and apply it smoothly on the paper),

- resins and additives (to adjust the different ink properties).

The diversity of compounds used in each categories of ingredients, combined with production impurities, is particularly interesting in a forensic identification perspective [8]. In practice, ballpoint pen inks (developed in 1930s [2]) are still the most commonly encountered in caseworks, together with inkjet and toner printers.

Before discussing the emerging technologies for the analysis of ink on questioned documents, it is important to clarify the purposes of such analysis. The following issues can arise during forensic investigation and judiciary processes:

- Ink identification to determine the (type of) device at the source of a manuscript or printer text.

- Differentiation of ink entries to detect an added or modified text using a different writing instrument or printer.

- Ink traces enhancement to read erased, faded or latent ink lines on a document.

- Sequencing of ink line crossings to determine in which chronological order some texts were added to a document.

- Dating of ink entries to estimate the moment of apposition of a text on a document. 


\section{Chapter 11: Emerging approaches in the analysis of inks on questioned documents}

Weyermann Céline, Techabowornkiat Korn-usa, 2019/10/01. dans In: Francese S. (eds) Emerging Technologies for the Analysis of Forensic Traces. Advanced Sciences and Technologies for Security Applications, Springer, Cham.

While identification of the source of an ink entry would be particularly useful in questioned documents, it is generally only possible to determine the type of ink and its main components depending on the selected examination techniques [8]. Thus, it is possible with a low magnification microscope to determine that a ballpoint pen was used to draw an ink line, while chromatographic methods will help determine that the dye basic violet and the solvent phenoxethanol were contained in the questioned ink. However, in practice, the brand, model and specific device remains generally unknown in the identification process [9]. Thus, it is rarely possible to determine from the examination of an ink entry that a bic cristal pen belonging to $M r s X$ was used to draw the questioned ink entry. This can be explained by the fact that inks are widely spread manufactured products evolving over time and across countries. In fact, ink manufacturers might sell their products to several pen brands. Thus, many undifferentiable bic cristal pens were produced using the same ink bulk, which might have been used as well to produce other pen brands and models sold in different countries. In parallel, the bic cristal pen on the desk of Mrs X probably contains different colorants and solvents than the one she bought 10 years ago or than the one of her colleague bought at the same time in another country [10]. Such problems are typically forensic and cannot be entirely solved through technological developments.

Some criteria and general principles are also particularly important in forensic science to insure the quality of the applied and emerging methodologies [11,12]:

- From general to particular: observation to the naked eye will always precede further magnification using a microscope.

- From non-destructive to destructive: it is important to minimise the alteration of the document as much as possible, so that the document can still be employed, remain readable, as well as to allow subsequent analyses (e.g. to increase knowledge or allow a counter-expertise). Thus, methods should be non-invasive (i.e. no alteration) or minimally invasive (i.e. only a minimal portion of the ink or paper is altered); this is why optical methods will generally precede chemical methods requiring an extraction.

- Reliability: the precision and accuracy of the methods must be determined and minimised. It is particularly important to carry out replicate analyses to estimate the reproducibility of the technique (as well as the intra-variability of the examined ink specimens). Control samples, such as standards, must also regularly be analysed to calibrate the instruments.

- Selectivity: the capacity of the method to discriminate between ink samples of different composition is particularly important to identify and compare ink entries. The discriminating power can be calculated using data acquired through the analysis of inks having the same source (i.e. intra-variability) in comparison to inks having different sources (i.e. inter-variability). 


\section{Chapter 11: Emerging approaches in the analysis of inks on questioned documents}

Weyermann Céline, Techabowornkiat Korn-usa, 2019/10/01. dans In: Francese S. (eds) Emerging Technologies for the Analysis of Forensic Traces. Advanced Sciences and Technologies for Security Applications, Springer, Cham.

Complementary methods, yielding a combined improved discriminating power, can be particularly useful.

- Sensitivity: the limits of detection and quantification must be determined for qualitative and quantitative analysis, respectively. While a sensitive method might be considered an advantage to analyse small quantities of material, background will often increase proportionally with this criteria and reliability of the method might thus be a more important criteria.

Of course, the simplicity, rapidity, hazard, portability and cost of the methods are also important practical criteria, as well as the ethical appropriateness of its application and interpretation in a legal context. Taking into account all these criteria several methods can then be selected and applied in sequence to examine the ink traces with the objective to answer the questions asked in a specific casework. Thus, while optical methods will always be preferred in a first stage, emerging (potentially invasive) technologies might bring useful additional information in some particular cases.

\subsection{Current ink analysis methods}

Together with the developments of ink composition and writing instruments, forensic methods have also evolved quickly during the past century. Of course, examination of documents was first carried out with the naked eye, and then using a magnifying glass which was certainly the first technological evolution in the examination of writings in questioned documents. The microscope is still a very important optical tool to observe and analyse all kinds of traces, including inks $[5,13]$. While gallotannic inks remained difficult to differentiate based on optical observations due to their very similar compositions, the question of artificial and natural aging was also discussed. Visible changes were reported such as the progressive darkening and cracking of the ink lines over time $[3,4]$. Microchemical spot tests were also reported in the first questioned documents manuals dealing with ink analysis $[5,13]$. They were used to compare dissolution rates and colour changes by adding some solvents and reagents to the ink lines in a minimally invasive way using a microscope. Filtered light and spectroscopic examinations were also proposed by the same authors to compare inks entries in a standardised way. While optical and spectroscopic devices are still the main (and often, the only) instrumentation employed for questioned document examinations, microchemical methods are no longer used . In the 1950s, paper chromatography and electrophoresis were proposed to separate and identify dyes and pigments [14]. These have then been replaced by more advanced techniques such as thin layer chromatography (TLC), liquid chromatography (LC) and capillary electrophoresis (CE) during the second part of the $\mathrm{XX}^{\mathrm{e}}$ century [15]. While many novel and highly technological techniques emerged these past years [16,17], TLC and high performance (HP)TLC are still the most common (and probably the cheapest) chemical methods used in forensic laboratories around the world (Figure 


\section{Chapter 11: Emerging approaches in the analysis of inks on questioned documents}

Weyermann Céline, Techabowornkiat Korn-usa, 2019/10/01. dans In: Francese S. (eds) Emerging Technologies for the Analysis of Forensic Traces. Advanced Sciences and Technologies for Security Applications, Springer, Cham.

7.1). (HP)TLC results were implemented in two of the largest ink libraries in Germany and the USA $[18-20]$.

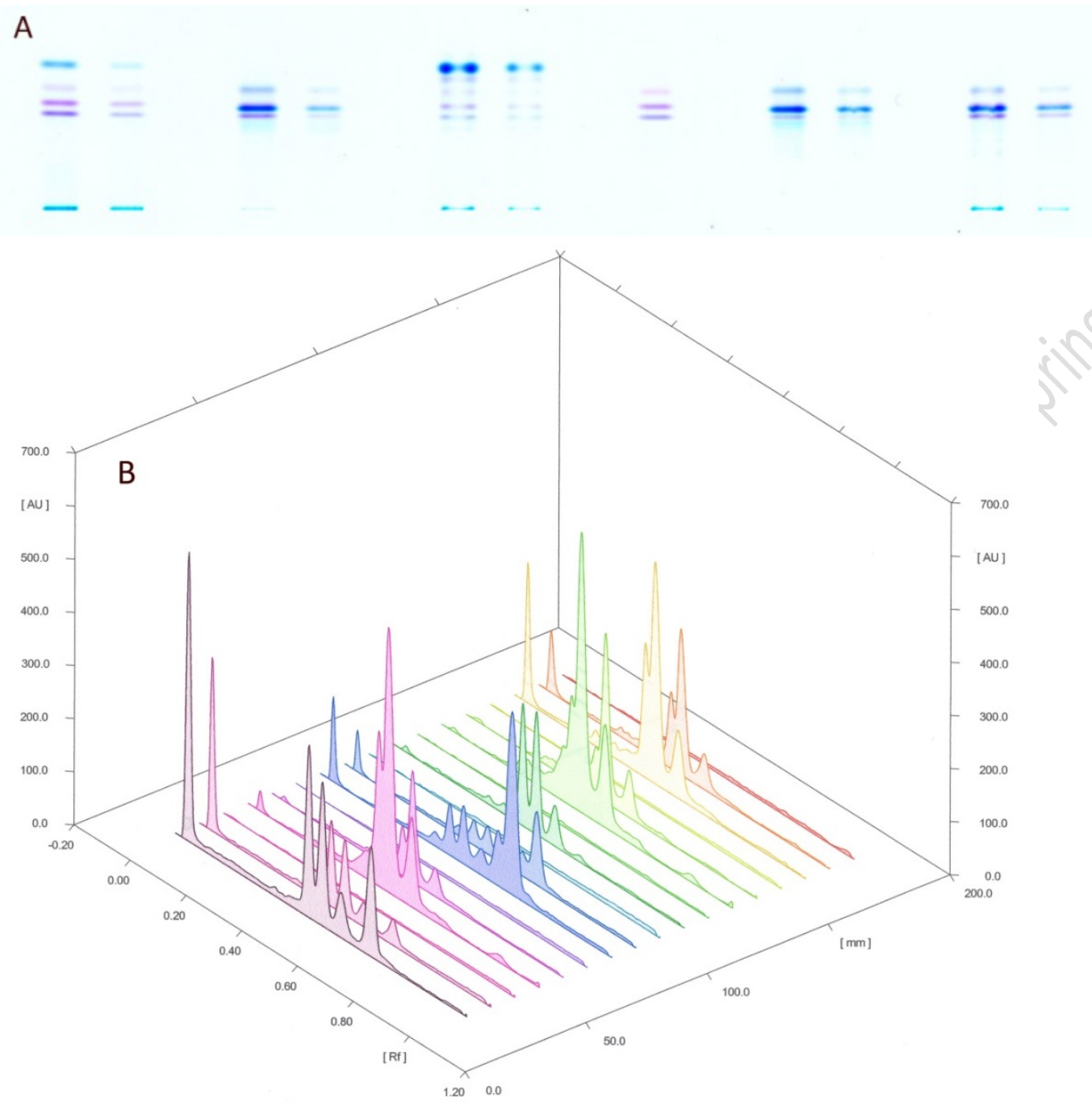

Figure 7.1 HPTLC plate results for the analysis of 5 blue pen ink samples (each in duplicate) and one basic violet 4 reference using a CAMAG Linomat 4 TLC spot applicator (A) and a CAMAG TLC 3D scan to report the density as a function of the retention factor (Rf) for the 11 spots (B).

Based on ink analysis methods reported in the literature [16,17], a proposition of the most promising approaches for ink comparison is made here and discussed. Paper analysis was not considered in this chapter, neither were ink dating and ink line sequencing [17,21,22] asit is well known that the potential of optical methods remains very limited for the purpose of ink dating and sequencing. To date, the most promising technique relies on solvents analysis for ink dating purposes using gas chromatography (GC) or liquid chromatography (LC) coupled to mass spectrometry (MS) $[23,24]$. For 


\section{Chapter 11: Emerging approaches in the analysis of inks on questioned documents}

Weyermann Céline, Techabowornkiat Korn-usa, 2019/10/01. dans In: Francese S. (eds) Emerging Technologies for the Analysis of Forensic Traces. Advanced Sciences and Technologies for Security Applications, Springer, Cham.

ink line sequencing, 3D laser profilometry might be an interesting complement to optical approaches. However, no methodologies was reported as validated yet for practical purposes [25].

While all kinds of potentially interesting technologies that can be useful for ink analysis and discrimination are reported in the literature, few studies actually reported large population studies. These would allow evaluating their actual capabilities and added value compared to traditional methods. A list of studies reporting the discrimination power of the techniques on various ink populations was compiled in Table 7.1. While most methods focused on the analysis of the visible coloured part of the inks (dyes and/or pigments), others targeted resins, additives, solvents and/or elemental composition. As mentioned above, non-invasive or minimally invasive techniques will generally be preferred in practice. Thus, optical and spectroscopic techniques generally remain the most interesting alternatives in a forensic context.

After observation under different magnification, the first applied technique in questioned document examination is generally filtered light examination (FLE). It is generally available in all laboratories and video spectral comparators (VSC) were developed by several companies to facilitate and automate the use of this method. Results can be easily saved as images. This technique is often used for preliminary examination of questioned documents, and will allow direct comparison of the optical properties of ink entries through the combination of different illumination and observation wavelengths (from ultraviolet to infrared light). Significant differences such as luminescence compared to absorption or transparency can be easily interpreted, while slight differences of the same optical characteristic (strong compared to medium luminescence) will be more challenging to evaluate as they may also be due to other influencing factors such as a slightly altered pressure while writing (Figure 7.2).
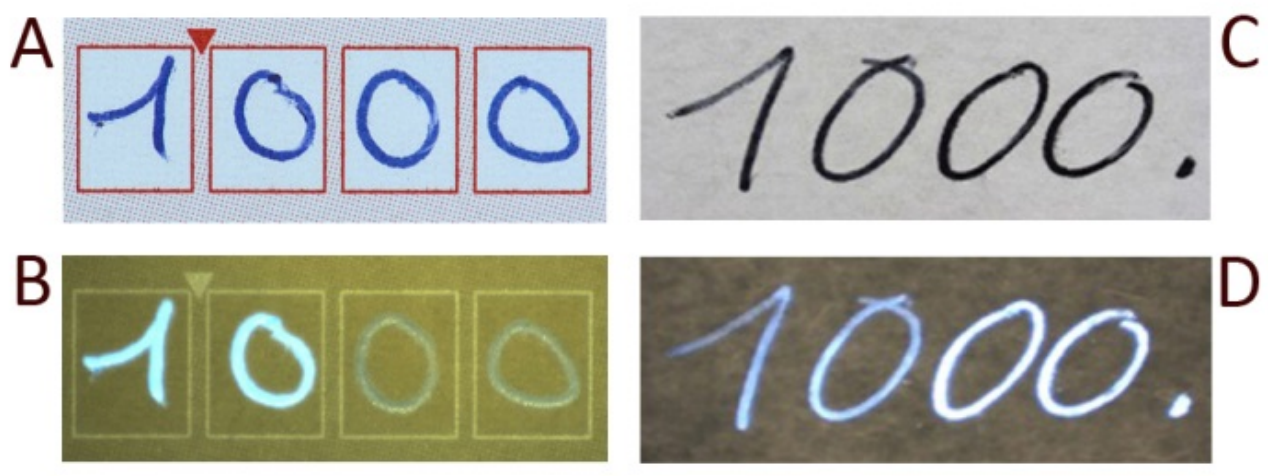

Figure 7.2 Blue and black ballpoint pens were used to draw the numbers "1000" on paper and observed using a Docucenter Nirvis PIA7000 from Projectina (Switzerland): (A-C) images taken under white light, (B-D) images resulting from excitation at a wavelength range of $550-650 \mathrm{~nm}$ and emission at $735 \mathrm{~nm}$. The difference of fluorescence observed in the blue pen image (B) clearly indicate that two pens were used, while the slight difference of fluorescence in the black pen image (D) might not suffice to indicate that two different pens were used as it might also come from a stronger pressure applied in the writing of the last two digits. 
Chapter 11: Emerging approaches in the analysis of inks on questioned documents

Weyermann Céline, Techabowornkiat Korn-usa, 2019/10/01. dans In: Francese S. (eds) Emerging Technologies for the Analysis of Forensic Traces. Advanced Sciences and Technologies for Security Applications, Springer, Cham.

The evaluation of the observed optical properties of the inks under different illumination and observation filters remains mainly visual and subjective. Therefore, only few quantitative results have been reported on the discriminating power of such approaches. Four studies reported discriminating power between 49 and $99 \%$ for ballpoint and gel pens [26-29]. While the discriminating power obtained for gel inks are lower than those obtained for ballpoint inks, the differences might also be due

\begin{tabular}{|c|c|c|c|c|c|c|}
\hline Techniques & $\begin{array}{l}\text { Type and \# of } \\
\text { inks }\end{array}$ & $\begin{array}{l}\text { Discriminating } \\
\text { Power }(\%)\end{array}$ & Invasive & Costs & Complexity & References \\
\hline FLE & $\begin{array}{l}49 \text { blue BP } \\
42 \text { black BP } \\
30 \text { black GP } \\
15 \text { black GP } \\
50 \text { blue BP } \\
\end{array}$ & $\begin{array}{l}83 \\
96 \\
49 \\
68 \\
>95(\mathrm{~S}) \\
\end{array}$ & no & minimal & minimal & $\begin{array}{l}{[26]} \\
{[26]} \\
{[27]} \\
{[28]} \\
{[29]}\end{array}$ \\
\hline MSP & $\begin{array}{l}49 \text { blue BP } \\
42 \text { black BP } \\
30 \text { black GP } \\
12 \text { blue BP } \\
21 \text { black BP } \\
\end{array}$ & $\begin{array}{l}83 \\
83 \\
74 \\
79 \\
96 \\
\end{array}$ & no & + & 3 & $\begin{array}{l}26] \\
{[26]} \\
{[27]} \\
{[30]} \\
{[30]}\end{array}$ \\
\hline HSI & $\begin{array}{l}15 \text { blue GP } \\
14 \text { black GP } \\
45 \text { black GP }\end{array}$ & $\begin{array}{l}90 \\
38 \\
60(\mathrm{~S}) \\
\end{array}$ & no & +5 & ++ & $\begin{array}{l}{[31]} \\
{[31]} \\
{[32]}\end{array}$ \\
\hline $\begin{array}{l}\text { (micro) } \\
\text { Raman }\end{array}$ & $\begin{array}{l}15 \text { black GP } \\
36 \text { blue GP } \\
17 \text { blue GP } \\
14 \text { blue BP } \\
23 \text { coloured IP } \\
27 \text { blue BP } \\
23 \text { black BP } \\
26 \text { blue BP } \\
26 \text { black BP } \\
63 \text { blue FI } \\
60 \text { black FI } \\
16 \text { blue BP } \\
\end{array}$ & $\begin{array}{l}77 \\
68 \\
89 \\
98(\mathrm{~S}) \\
94 \\
92 \\
91 \\
47 \\
58 \\
47 \\
74 \\
88 \\
\end{array}$ & no & $U^{\prime}$ & ++ & $\begin{array}{l}{[28]} \\
{[33]} \\
{[34]} \\
{[35]} \\
{[36]} \\
{[37]} \\
{[37]} \\
{[38]} \\
{[38]} \\
{[38]} \\
{[38]} \\
{[39]}\end{array}$ \\
\hline SERS & $\begin{array}{l}15 \text { black GP } \\
26 \text { blue BP } \\
26 \text { black BP } \\
63 \text { blue FI } \\
60 \text { black FI } \\
13 \text { blue FI }\end{array}$ & $\begin{array}{l}90 \\
80 \\
33 \\
83 \\
92 \\
75 \\
\end{array}$ & yes & ++ & +++ & $\begin{array}{l}{[28]} \\
{[38]} \\
{[38]} \\
{[38]} \\
{[38]} \\
{[40]}\end{array}$ \\
\hline (ATR) FTIR & $\begin{array}{l}27 \text { blue BP } \\
23 \text { black BP } \\
8 \text { blue BP } \\
54 \text { toners }\end{array}$ & $\begin{array}{l}90 \\
94 \\
63(\mathrm{~S}) \\
90\end{array}$ & (yes) no & ++ & ++ & $\begin{array}{l}{[37]} \\
{[37]} \\
{[41]} \\
{[42]}\end{array}$ \\
\hline TLC & $\begin{array}{l}49 \text { blue BP } \\
42 \text { black BP } \\
16 \text { blue BP } \\
7 \text { blue BP } \\
10 \text { blue BP } \\
9 \text { black BP } \\
41 \text { blue BP } \\
\end{array}$ & $\begin{array}{l}98 \\
99 \\
96 \\
87 \\
82 \\
81 \\
83(\mathrm{~S}) \\
\end{array}$ & yes & minimal & minimal & $\begin{array}{l}{[26]} \\
{[26]} \\
{[39]} \\
{[28]} \\
{[43]} \\
{[43]} \\
{[44]}\end{array}$ \\
\hline HPTLC & 31 blue BP & 92 & yes & + & + & [45] \\
\hline HPLC & 8 blue BP & $98(\mathrm{~S})$ & yes & ++ & +++ & [41] \\
\hline LDI-MS & $\begin{array}{l}31 \text { blue BP } \\
33 \text { blue BP } \\
33 \text { blue GP } \\
30 \text { blue GP } \\
10 \text { IJ }\end{array}$ & $\begin{array}{l}99 \\
99 \\
92(\mathrm{~S}) \\
85(\mathrm{~S}) \\
95(\mathrm{~S}) \\
\end{array}$ & minimal & +++ & ++ & $\begin{array}{l}{[45]} \\
{[46]} \\
{[47]} \\
{[48]} \\
{[49]}\end{array}$ \\
\hline DART-MS & $\begin{array}{l}28 \text { blue BP } \\
48 \text { black BP } \\
19 \text { blue GP } \\
21 \text { black GP } \\
\end{array}$ & $\begin{array}{l}100(\mathrm{~S}) \\
99(\mathrm{~S}) \\
97(\mathrm{~S}) \\
93(\mathrm{~S})\end{array}$ & minimal & +++ & ++ & {$[50]$} \\
\hline LIBS & $\begin{array}{l}34 \text { blue inks } \\
30 \text { black inks }\end{array}$ & $\begin{array}{l}83 \\
82 \\
\end{array}$ & minimal & ++ & ++ & $\begin{array}{l}{[51]} \\
{[51]}\end{array}$ \\
\hline
\end{tabular}


Chapter 11: Emerging approaches in the analysis of inks on questioned documents

Weyermann Céline, Techabowornkiat Korn-usa, 2019/10/01. dans In: Francese S. (eds) Emerging Technologies for the Analysis of Forensic Traces. Advanced Sciences and Technologies for Security Applications, Springer, Cham.

\begin{tabular}{|c|c|c|c|c|c|c|}
\hline & $\begin{array}{l}11 \text { black GP } \\
21 \text { black IJ } \\
27 \text { black toners }\end{array}$ & $\begin{array}{l}96(\mathrm{~S}) \\
94(\mathrm{~S}) \\
89(\mathrm{~S}) \\
\end{array}$ & & & & $\begin{array}{l}{[52]} \\
{[53]} \\
{[53]}\end{array}$ \\
\hline (LA) ICP-MS & $\begin{array}{l}21 \text { blue BP } \\
22 \text { black BP } \\
29 \text { black GP } \\
21 \text { black IJ } \\
27 \text { black toners }\end{array}$ & $\begin{array}{l}96(\mathrm{~S}) \\
99(\mathrm{~S}) \\
98(\mathrm{~S}) \\
98(\mathrm{~S}) \\
100(\mathrm{~S})\end{array}$ & yes & +++ & +++ & $\begin{array}{l}{[54]} \\
{[52]} \\
{[52]} \\
{[53]} \\
{[53]}\end{array}$ \\
\hline ToF-SIMS & 24 blue BP & $91(\mathrm{~S})$ & yes & +++ & +++ & [55] \\
\hline GC-MS & 32 blue BP & 94 & yes & ++ & ++ & [56] \\
\hline $\begin{array}{l}\text { (LA) Py GC- } \\
\text { MS }\end{array}$ & 8 black toners & $100(\mathrm{~S})$ & yes & +++ & +++ & [57] \\
\hline
\end{tabular}

Table 7.1 - Selected researches mentioning the discriminating power (DP) of the evaluated techniques. Costs was indicated in a comparative way including maintenance (depending on the instrument brand, model and options, the actual costs can significantly vary). Simplicity is rarely mentioned in the literature and was indicated based on the knowledge and experience of the authors (and may also vary depending on the instrument options and evolution). BP, GP, IP and FI means ballpoint pens, gel pens, inkjet printers and fluid inks, respectively. (S) indicates the use of statistics to calculated the indicated discriminating powers. As can be seen, statistical treatments were more frequently applied on data acquired by advanced technologies. References were found from several sources, such as Scopus, the university library and review articles.

to different sample size and origin. A recent study proposed to evaluate the potential of FLE using chemometrics $^{3}$ to discriminate 50 blue ballpoint pen inks [29]. Different combinations of illumination and observation settings were selected statistically and yielded a discriminating power above $95 \%$. Improving the image classification through automated systems, or using semi-quantitative spectroscopic approaches such as microspectrophotometry (MSP) or hyperspectral imaging (HSI) combined to statistical data treatment might represent the most efficient emerging technologies for ink analysis and comparison (Figure 7.3). Such approaches are non-invasive, relatively simple and easy to automate. They also remain economic and selective as demonstrated by the reported discriminating powers in Table 7.1. The creation of a shared database would be feasible using the same validated and calibrated method between the different laboratories feeding the system [58]. Reported discriminating power for MSP ranged from 74 to $96 \%$ applying visual comparison of the obtained UV-VIS [26-28]. Recent developments proposed to add a spatial component to spectroscopic data obtained, through HSI [59]. While the spatial dimension is not per se useful for ink analysis, it has the advantage to directly take into account the surface irregularities that can occur on the surface of an ink entry due to its deposition on paper (and thus characterise the intra-variability of the inks' spectroscopic response). One study proposes a statistical methodology to discriminate two inks on a document using HSI [58]. However, only 5 blue and 5 black pens were evaluated (for a total of 10 possible combinations for each colour). While the proposed algorithmic approach might be interesting, it remains complex and

\footnotetext{
${ }^{3}$ Chemometrics is the use of statistical methods to extract useful information from chemical data.
} 


\section{Chapter 11: Emerging approaches in the analysis of inks on questioned documents}

Weyermann Céline, Techabowornkiat Korn-usa, 2019/10/01. dans In: Francese S. (eds) Emerging Technologies for the Analysis of Forensic Traces. Advanced Sciences and Technologies for Security Applications, Springer, Cham.

still far from forensic implementation. More inks should be analysed to evaluate the real potential of HSI. Two studies did report a discriminating power from 40 to $90 \%$ for the analysis of gel pens inks using HSI $[31,32]$.

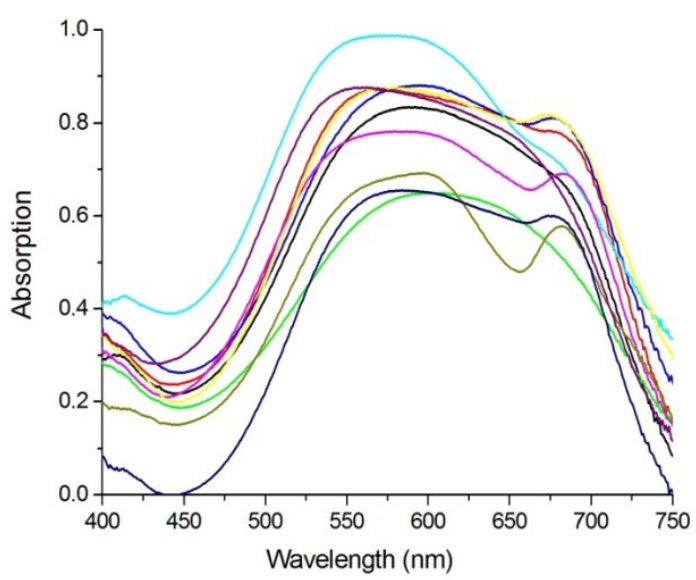

Figure 7.3 Mean absorption spectra of 10 blue ballpoint pen entries acquired using a Zeiss Axioskop instrument equipped with an Epilon - Neofluar objective 20x / $0.50 \mathrm{HD}$.

Other very interesting (to some extent non-invasive) technological approaches are offered by Raman ${ }^{4}$ and infrared (IR) spectroscopies (Figure 7.4). Gel pen inks and toners cannot be analysed using HPTLC as they generally do not contains dyes, but pigments (that are insoluble in the solvent systems used in HPTLC). Thus, Raman was proposed to analyse gel pen inks and inkjet printers [60-62], while Fourier Transform (FT)-IR was applied to discriminate toners $[63,64]$. Surface Enhanced Raman spectroscopy (SERS) ${ }^{5}$ was recommended to analyse dye-based inks in order to avoid fluorescence and enhance Raman signals [38]. Due to the small amount of reagent applied to the ink entry, the SERS technique can be considered as minimally invasive. Raman microspectroscopy and the use of multiple laser wavelengths were also suggested to increase performance and discrimination. Discriminating powers from 47 to $98 \%$ were reported in the literature $[28,33-38,40]$. Two studies concluded that the discriminating power was generally significantly higher using SERS [28,38]. Again the highest discriminating power was obtained for data treatment using chemometrics. Only one study reported a discriminating power for toner analysis using micro Attenuated Total Reflectance (ATR) ${ }^{6}$-FTIR and statistical treatments reaching $90 \%$ for 54 analysed samples [42]. Two other studies focused on the

\footnotetext{
${ }^{4}$ In brief, the Raman effect is a change in the wavelength of light occurring when a light beam is deflected by molecules, thus yielding information on the structure of the targeted molecules.

${ }^{5}$ SERS allows to increase the RAMAN signal of several orders of magnitude (and thus, the sensitivity if the technique) through a particular sample preparation that allow molecules to be adsorbed on metallic surfaces typically made of gold or silver.

${ }^{6}$ ATR is a sampling technique using a crystal to reflect the infrared beam of light. It allows measuring surface properties with no sample preparation and for absorbing material it additionally increases the IR signal.
} 


\section{Chapter 11: Emerging approaches in the analysis of inks on questioned documents}

Weyermann Céline, Techabowornkiat Korn-usa, 2019/10/01. dans In: Francese S. (eds) Emerging Technologies for the Analysis of Forensic Traces. Advanced Sciences and Technologies for Security Applications, Springer, Cham.

analysis of ballpoint inks [37,41]. Interestingly, the lowest discriminating power (63\%) was obtained for 8 blue inks spectra compared through statistical treatments using replicate analyses from different pens of the same brand. This indicates that taking into account the statistical variability of a given ink (i.e. the intra-variability of the specimens) might reduce significantly the discriminating power.
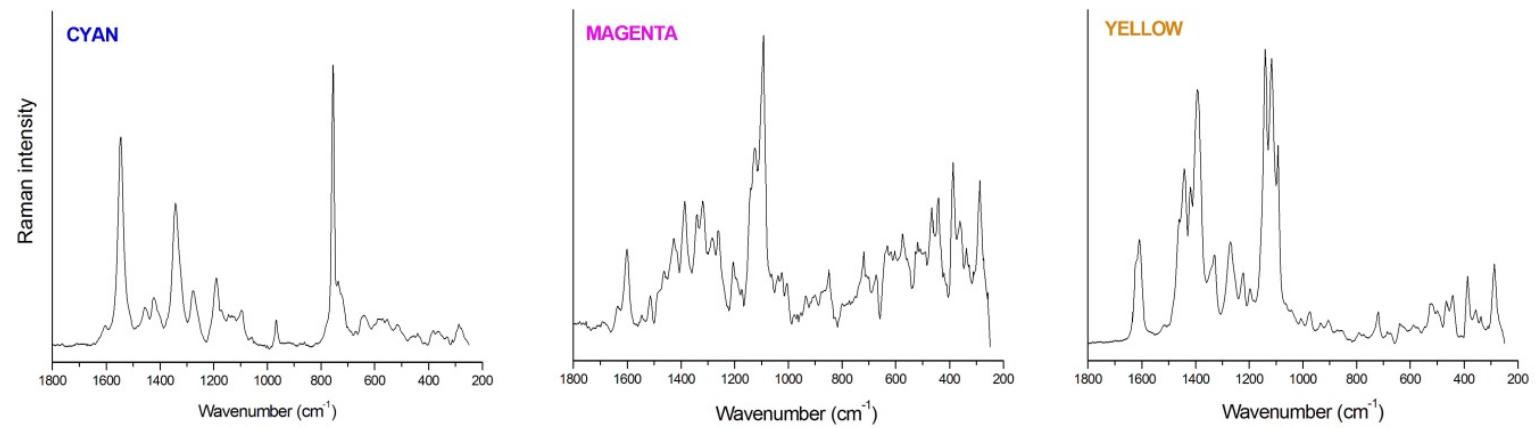

Figure 7.4 Raman spectra of the cyan, magenta and yellow components of the ink from an inkjet printer. Spectra have been acquired using a Horiba Scientific instrument equipped with a diode-array near-infrared laser at 785 $\mathrm{nm}[62]$.

Separation techniques are generally used only if optical and spectroscopic techniques did not allow ink discrimination. Thin layer chromatography $(T L C)$ is generally available in all forensic laboratories. It is a very cost effective and simple method, showing a very good discriminating power from 81 to $99 \%$ $[26,28,39,43,44]$. HPTLC is a technological development that allows automatic sample deposition on the high performance plate. The chromatographic analysis is followed by an automatic scan yielding a densitometric analysis (Figure 7.1) either in absorbance or luminescence mode [45]. This setup increases the cost and complexity of the analysis in parallel to the reliability of the results. One major drawback of HPTLC is that it does not work for pigmented inks and necessitates up to $1 \mathrm{~cm}$ ink to be extracted from the document. Thus, it is an invasive technique that requires authorization from the mandator. Finally, it was observed that the creation of a library has to be controlled using strict standardized conditions and references, as the elution distance can vary significantly between runs and was thus not always reliable [18].

Other more advanced techniques were proposed such as high-performance liquid chromatography (HPLC) and capillary electrophoresis (CE) using different detectors. Pigments and solvents can thus be analysed using the same technique. Even resins can be detected using advanced ultra-performance $L C$ coupled to a MS detector (UPLC-MS). However, up-to-date only one study reported a discriminating power of $98 \%$ using HPLC [41]. Gas chromatography coupled to a mass spectrometer $(G C-M S)$ is used for the analysis of volatile compounds such as ink solvents. While solvents decrease rapidly in the ink entries, it can be used for ink differentiation as indicated by the discriminating power of $94 \%$ obtained from the qualitative data reported for the analysis of 32 ballpoint pen inks [56]. 


\section{Chapter 11: Emerging approaches in the analysis of inks on questioned documents}

Weyermann Céline, Techabowornkiat Korn-usa, 2019/10/01. dans In: Francese S. (eds) Emerging Technologies for the Analysis of Forensic Traces. Advanced Sciences and Technologies for Security Applications, Springer, Cham.

Adding quantitative determination of the solvent amount in the ink line might increase the potential of the method for ink discrimination. Thermal desorption (TD) GC/MS can furthermore detect resin compounds [65].

Several mass spectrometry (MS) techniques were also applied to ink analysis [17]. Laser desorption ionization (LDI) and direct analysis in real time (DART)-MS enable the mass spectral identification of key ink components (Figure 7.5) and discriminating power up to $99 \%$ and minimal invasiveness were reported in the literature [45-50]. However, the use of chemometrics to treat the data taking into account the intra-variability (i.e. the variability among specimens coming from the same source ink) tend to show slightly lower (and probably more realistic) discriminating power values (Table 7.1).
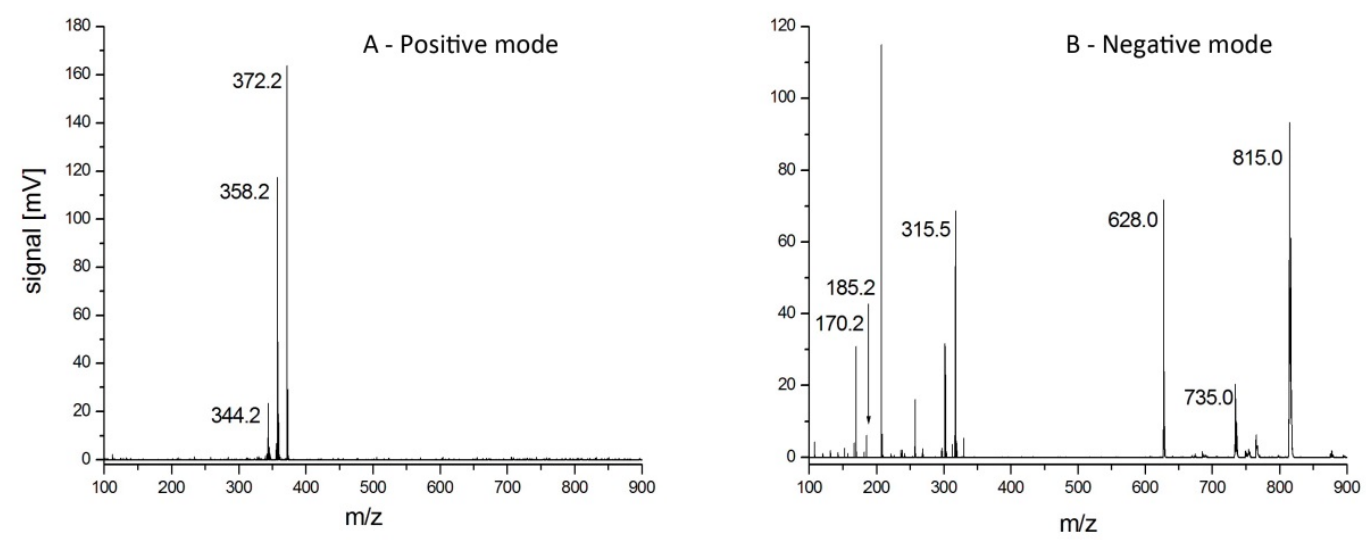

Figure 7.5 LDI spectra of a blue ballpoint pen entry analysed directly on a piece of paper [46]. Basic violet 3 $(\mathrm{m} / \mathrm{z}=344.2,358.2$ and $372.2 \mathrm{u})$ was identified in the positive mode $(\mathrm{A})$, while acid blue $9(\mathrm{~m} / \mathrm{z}=170.2$ and $185.2 \mathrm{u})$, acid blue $92(\mathrm{~m} / \mathrm{z}=313.5$ and $628.0 \mathrm{u})$ and solvent blue 38 and its mono-sulfonic acid derivative $(\mathrm{m} / \mathrm{z}=$ $735.0 \mathrm{u}$ and and $815.0 \mathrm{u}$ ) were detected in the negative mode $(\mathrm{B})$.

Finally, elemental composition analysis was additionally evaluated for ink discrimination [17]. X-ray fluorescence $(X R F)$ is generally more often available in forensic laboratories, but no studies calculated a discriminating power using this method. Laser induced breakdown spectroscopy (LIBS) yielded discriminating power from 82 to $96 \%$ [51-53]. More advanced methods were applied to ink differentiation such as laser ablation inductively coupled (LA-ICP)-MS, time-of-flight secondary ion (ToF-SI)-MS, Laser ablation pyrolysis (LA-Py) GC-MS or Scanning Electron Microscopy-Energy Dispersive spectroscopy (SEM-EDS).

While SEM-EDS yielded really poor discriminating powers, the others allowed from 90 to $100 \%$ discrimination using chemometrics [53-55]. However, these methods are very complex, expensive and to some extent invasive. They will generally not be available in forensic laboratories. 
Chapter 11: Emerging approaches in the analysis of inks on questioned documents

Weyermann Céline, Techabowornkiat Korn-usa, 2019/10/01. dans In: Francese S. (eds) Emerging Technologies for the Analysis of Forensic Traces. Advanced Sciences and Technologies for Security Applications, Springer, Cham.

An interesting emerging technology for ink analysis might reside in the coupling of Raman and SEM$E D X$, combining to kind of information in one experimental design [66]. However, it was not tested yet for ink analysis purposes.

\subsection{Emerging techniques}

While many advanced techniques have been listed and discussed above, two kind of emerging technologies can be highlighted as particularly promising for ink analysis in view of the evolution of ink formulation.

1) Optical and spectroscopic methods, such as HSI, Raman and IR spectroscopy have the advantage of meeting most of the constraints within an operational forensic context: they are non-invasive, reliable, selective, sensitive, simple, rapid, economic and safe for the health of the examiners. Some instruments can even be transported on a crime scene and offer imaging capabilities [59,67-72]. Spectra can easily be stored in a database and shared by forensic laboratories at the condition that the instrument measurements are calibrated using certified standards to insure comparability of the results [73]. While visual comparison of the spectra was generally used in routine work, the amount of data generated by imaging techniques will necessitate powerful data treatment software and chemometrics in order to visualise and compare results (Figure 6). Raman and IR spectroscopy are often already available in forensic laboratories for other applications such as paint, drugs or fibre analysis, and thus can be easily transferred to ink analysis. HSI modalities are now directly integrated in the latest models of Video Spectral Comparator, an instrument that is routinely used by questioned document examiners around the world [71]. As shown in Table 7.1, all three techniques showed very promising discriminating power and are to some extent complementary in terms of targeted ink type. HSI might be less discriminating, but more versatile. Raman will generally be preferred to analyse pigment containing ink entries made for example from gel pens or inkjet printers $[33,62]$, and IR spectroscopy will be particularly adapted to inks containing resins such as toners [74]. Portable instruments will also have the advantages of being easier to use and thus implementable in smaller forensic laboratories at reduced costs. The resulting discriminating power might be lower, but the portability developments are expected in the near future to make these instruments a viable alternative to present examination techniques. 


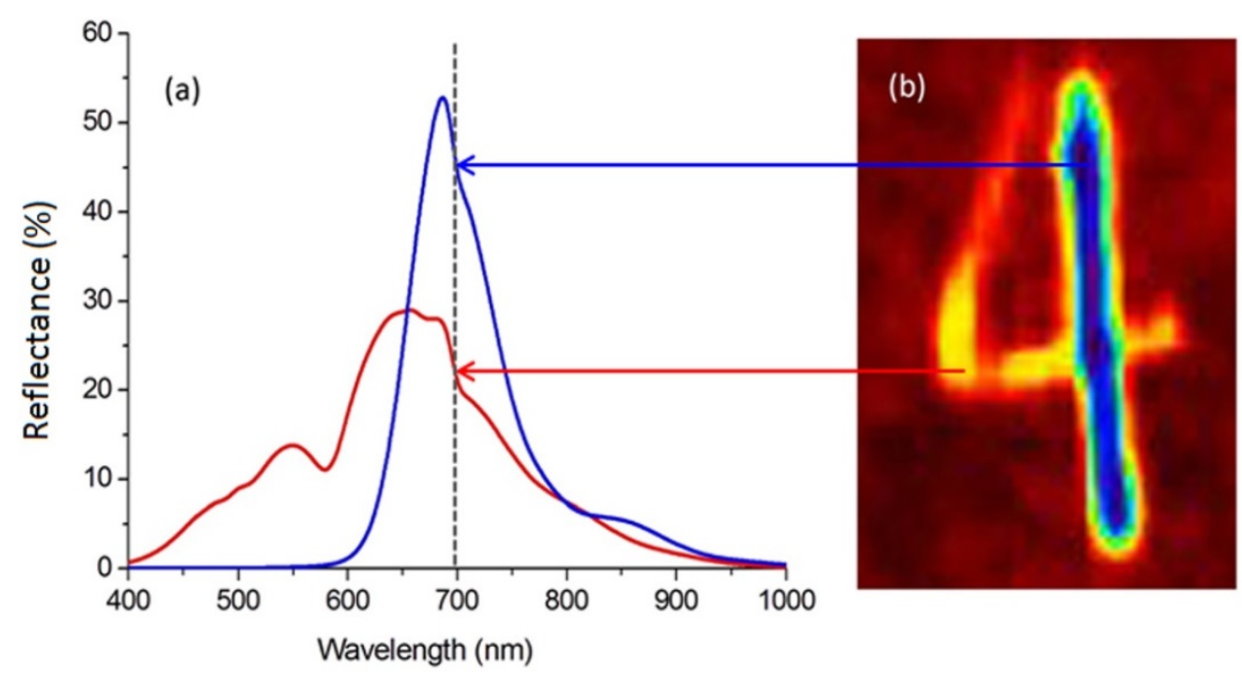

Figure 7.6 The number four was drawn using two blue ballpoint pens: (a) Reflectance spectra acquired using a Docucenter Nirvis PIA7000 from Projectina. (b) Hyperspectral imaging at wavelength $700 \mathrm{~nm}$ acquired using a Spectral Camera sCMO from SPECIM.

2) If the discriminating power has to be increased, chemical methods might be considered in a second analytical stage. Amongst them, the least invasive would be mass spectrometry techniques using minimally invasive desorption. LDI-MS was first proposed for ink analysis [75] and showed promising discriminating power (Table 7.1 and Figure 7.3). As vacuum is needed to ionize the samples, ink entries generally have to be cut from the paper and inserted in the ionization chamber, where solvents will be rapidly evaporated. Even so, LDI-MS can be considered as being minimally invasive, as the ink line can still be analysed to detect colorants and additives using LDI-MS or HPTLC. The use of a matrix might increase the selectivity and sensitivity of the method, but it would add to the invasiveness of the sample preparation [49]. The emergence of ambient ionization MS represents a very interesting development in terms of minimising invasiveness as the ink is sampled directly from a document substrate without the need to cut out the paper substrate and showing no or minimally visible alteration. Direct electrospray ionization (DESI), Direct Sample Analysis (DSA) and Direct Analysis in Real Time (DART) are different types of ambient ionisation options [50,76-78]. DESI was first reported and involves a solvent being electrosprayed to generate charged droplets that are directed at the ink sample directly on paper [76]. While LDI and DESI allow imaging of the samples, DESI was not further applied to the analysis of ink. This might be due to the fact that it is less user-friendly and sensitive than LDI-MS. Thus, the potential of other ambient MS technologies were tested and compared. DSA ${ }^{7}$ and DART ${ }^{8}$ actually produce

\footnotetext{
${ }^{7}$ DSA uses a ion gun that direct heated nitrogen gas molecules at the samples in a mesh holder.

${ }^{8}$ DART uses stream of excited helium or nitrogen to ionize samples directly on the paper substrate.
} 


\section{Chapter 11: Emerging approaches in the analysis of inks on questioned documents}

Weyermann Céline, Techabowornkiat Korn-usa, 2019/10/01. dans In: Francese S. (eds) Emerging Technologies for the Analysis of Forensic Traces. Advanced Sciences and Technologies for Security Applications, Springer, Cham.

similar ink spectra (Figure 7.7) [77]. While DSA-MS generates less background signal, the open source configuration of DART-MS provides more flexibility for sample positioning and size, thus yielding a better sensitivity. Both techniques showed comparable repeatability. In comparison to LDI-MS, smaller molecules including more volatile compounds dominate the acquired mass spectra. This represents both an advantage and a disadvantage. Indeed, the techniques are less invasive and can detect ink solvents additionally to dyes. However, the ink composition profiles are modified over time as solvents evaporates [50]. As long as the ink samples are compared at the time of on the same document, this does not represent a major issue. On the contrary, age differences might even highlight an addition made with the same pen but at a different time (Figure 7.2). However, this is also a hindrance to the implementation of a database as different mass spectra can be acquired over time for the same ink. Thus, it necessitates the identification of peaks in the spectra (i.e. ink components) showing stable relative areas, that will be extracted to feed into the database. This task can be automated using chemometrics approaches [79]. Machine learning algorithms might thus represent a promising development for the implementation of such techniques in practice. The main drawbacks of these emerging technologies lie in the costs and size of such instruments. Indeed, while the initial costs might already be an issue, the annual maintenance and consumable costs will generally not justify the purchase of such equipment solely for questioned document examination.
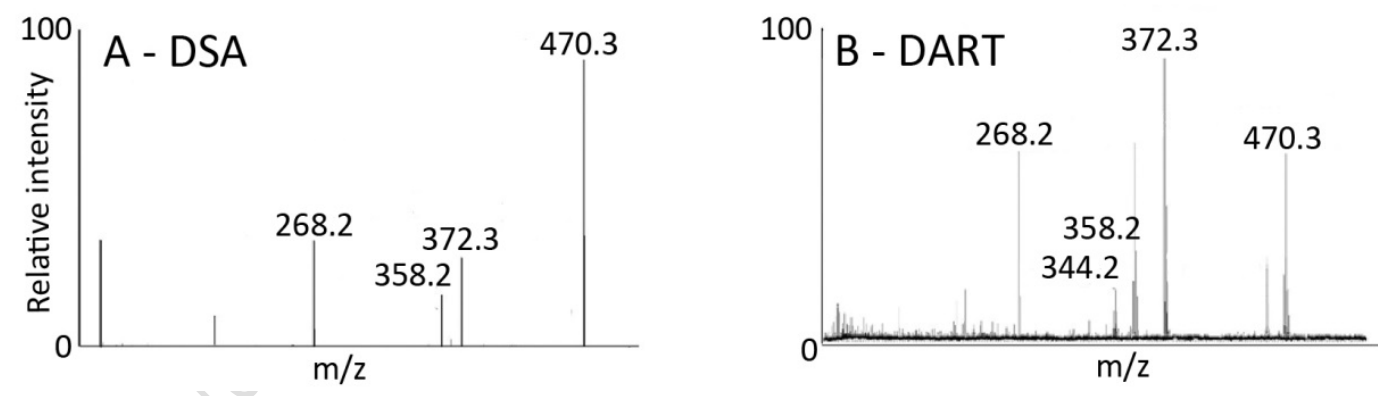

Figure 7.7 DSA (A) and DART (B) mass spectra of $5 \mathrm{~mm}$ blue ballpoint pen ink entries on paper. DSA analysis was performed on an AxION DSA in conjunction with an AxION 2 Time of Flight Mass Spectrometer from Perkin Elmer [78]. DART analysis was acquired with a DART 100 ion source from IonSense coupled to an AccuTOF JMST100LC mass spectrometer from JEOL and showed more background noise [77]. Michler's ketone $(\mathrm{m} / \mathrm{z}=269.4)$, basic violet $3(\mathrm{~m} / \mathrm{z}=344.2,358.2$ and 372.2) and basic blue $7(\mathrm{~m} / \mathrm{z}=470.2)$ were identified by both techniques.

While these emerging techniques represent very promising alternatives to presently used optical and chemical techniques, no reported study demonstrated that they actually yield better results in a forensic context yet [26]. This is due to the fact that most studies calculate the discriminating power of a set of 


\section{Chapter 11: Emerging approaches in the analysis of inks on questioned documents}

Weyermann Céline, Techabowornkiat Korn-usa, 2019/10/01. dans In: Francese S. (eds) Emerging Technologies for the Analysis of Forensic Traces. Advanced Sciences and Technologies for Security Applications, Springer, Cham.

ink samples from different brands bought on the market. There is actually no indication that the bought inks are really different or represent inks that would be encountered in forensic practice. Thus, discriminating powers calculated in the literature are only indicative and cannot be compared to those obtained in other studies (except when the same ink populations were used). In fact, calculated discriminating power might be influenced by the size of the ink population (i.e. the more, the better), by the selected samples (i.e. different type of inks, colours, brands, models), by the different techniques and experimental settings and finally by the different ways to compare results (i.e. qualitative or statistical approaches).

The fact that specimen variation is rarely taken into account in the discriminating power calculation is also a major concern in forensic science. It is essential to insure that the intra-variability of the ink specimen (i.e. the variability among specimens originating from the same ink) is significantly lower than the inter-variability (i.e. the variability between specimens originating from different inks) $[48,80]$. The discriminating power of studies taking into account the intra-variability often yields lower and more realistic discriminating power. Additionally, the development of objective comparison approaches (i.e. using transparent and easy-to-use statistical approaches) will also yield more reliable evidence for court purposes in comparison to subjective comparison of luminescence or TLC plate. The main remaining challenge will then be to present to a Court Raman or LDI results in a similar straightforward way than the luminescence images presented in Figure 7.2 or the TLC plate presented in Figure 7.1.

\section{Conclusion}

As it can be seen, despite the tremendous progress in technologies made these last years and the manifold techniques proposed in the literature $[16,17,81,82]$, most forensic laboratories still use very simple and economic techniques. One can ask why most forensic laboratories have not implemented these developments in practice. Several reasons can be suggested. From the personal experience of the authors, working in two operational forensic laboratories in Switzerland and Thailand, casework necessitating ink analysis, comparison or dating represent only a small part of the questioned document examinations compared to handwriting comparison or identity documents inspection. Even the examination of documents to detect potential falsifications or counterfeiting does rarely require ink analysis beyond optical comparison. This might be due to the fact that ink analysis rarely allows answering the key forensic questions. It is very useful to highlight differences, but the fact that two inks entries cannot be differentiated does not mean that the same pen was used. It may also indicate that a particular ink formulation is very common in the market. One can apply as many techniques as possible, such result will remain particularly difficult to interpret. Thus, it is also suggested by the authors that advanced methods might not be much more efficient to answer the right questions 


\section{Chapter 11: Emerging approaches in the analysis of inks on questioned documents}

Weyermann Céline, Techabowornkiat Korn-usa, 2019/10/01. dans In: Francese S. (eds) Emerging Technologies for the Analysis of Forensic Traces. Advanced Sciences and Technologies for Security Applications, Springer, Cham.

compared to traditional approaches. As too many resources (in terms of costs and qualified personal) might have to be invested for a slightly increased discriminating power, the investment is generally not worth the effort for small operational laboratories. Only larger national or central laboratories can implement such "emerging" and costly technologies that can then be applied to several other forensic applications. The main impact of such technologies might thus not lie in improved discriminating power, but in versatility (i.e., the possibility to analyse all type of ink composition), reliability (i.e., an objective approach to compare samples taking into account reproducibility of specimen analysis) and non-invasiveness (i.e. the possibility to analyse again the sample). Thus, the highlighted emerging technologies might bring a real impact in practice. Future researches should now attempt, not only to evaluate one method on limited ink samples, but also to compare the different promising approaches using large ink sample sets both, to help select and validate efficient and reliable methodologies, and to support evidence interpretation for judicial purposes. Finally, it is important to remind forensic scientists the importance of blind testing their own methodologies to ensure final validity for implementation in forensic practice [83].

\section{References}

1. Vignaud, C., Salomon, H., Chalmin, E., Geneste, J.-M., and Menu, M. (2006) Le groupe des «bisons adossés» de Lascaux. Étude de la technique de l'artiste par analyse des pigments. L'Anthropologie 110, 482-499

2. Levinson, J. (2001) Questioned Documents - A Lawyer's Handbook, Academic Press, London and California

3. Demelle, F. (1604) Advis, pour juger des inscriptions en faux \& comparaison des écritures \& signatures, pour en faire et dresser les moyens, veoir et descouvrir toutes falsifications et faulsetez, plus pour cognoistre et deschifrer les lettres cachées et occultes, Rene Ruelle, Paris

4. Raveneau, J. (1666) Traité des inscriptions en faux et reconnaissances d'écritures et de signatures par comparaison, Thomas lolly, Paris

5. Locard, E. (1959) Les faux en écriture et leur expertise, Payot

6. Cantù, A. A. (2009) Ink Analysis. in Wiley Encyclopedia of Forensic Science (Jamieson A., M. A. ed.), J. Wiley \& Sons. pp

7. Siegel, J. A. (2013) Ink Analysis. in Encyclopedia of Forensic Sciences, Academic Press, Waltham. pp 375-379

8. Neumann, C. (2013) Ink Comparison and Interpretation. in Wiley Encyclopedia of Forensic Science (A.., J. A. M. ed.), J. Wiley \& Sons (eds.). pp

9. Kirk, P. L. (1963) The Ontogeny of Criminalistics, 54 J. Crim. L. \& Criminology 235 (1963). . J. Crim. L. \& Criminology 54, 235-238

10. Aginsky, V. N. (2006) Using TLC and GC-MS to Determine whether Inks Came from the Same Manufacturing Batch. Journal of the American Society of Questioned Document Examiners 9, 19-27

11. Horwitz, W. (1982) Evaluation of analytical methods used for regulation of foods and drugs. Analytical Chemistry 54, 67-76 


\section{Chapter 11: Emerging approaches in the analysis of inks on questioned documents}

Weyermann Céline, Techabowornkiat Korn-usa, 2019/10/01. dans In: Francese S. (eds) Emerging Technologies for the Analysis of Forensic Traces. Advanced Sciences and Technologies for Security Applications, Springer, Cham.

12. Ribaux, O. (2014) Police scientifique: le renseignement par la trace, Presses polytechniques et universitaires romandes, Lausanne

13. Osborn, A. S. (1910) Questioned Documents, The Lawyers' Co-operative Publishing Company, Rochester, NY.

14. Brown, C., and Kirk, P. L. (1954) Paper Electrophoresis in the Identification of Writing Inks-Comparison with Horizontal Paper Chromatography. J. Crim. L. Criminology \& Police Sci. 45, 473-480

15. Chen, H. S., Meng, H. H., and Cheng, K. C. (2002) A survey of methods used for the identification and characterization of inks. Forensic Sci. J. 1, 1-14

16. de Koeijer, J. (2013) Analytical Methods A2 - Siegel, Jay A. in Encyclopedia of Forensic Sciences (Saukko, P. J., and Houck, M. M. eds.), Academic Press, Waltham. pp 342-350

17. Calcerrada, M., and García-Ruiz, C. (2015) Analysis of questioned documents: A review. Analytica Chimica Acta 853, 143-166

18. Neumann, C., Ramotowski, R., and Genessay, T. (2011) Forensic examination of ink by highperformance thin layer chromatography-The United States Secret Service Digital Ink Library. Journal of Chromatography A 1218, 2793-2811

19. Bügler, J. H., Graydon, M., and Ostrum, B. (2010) The practical use of the Munich ink reference collection in daily casework. in 6th European Document Examiners Working Group (EDEWG) Conference, Dubrovnik, Croatia

20. Bügler, J. H., Buchner, H., and Dallmayer, A. (2004) Differenzierung von Kugelschreiberpasten durch Thermodesorption und Gaschromatographie-Massenspektrometrie. Archiv für Kriminologie 214, 141-148

21. Fritz, T., and Nekkache, S. (2013) Paper Analysis. in Encyclopedia of Forensic Sciences (Second Edition) (Siegel, J. A., Saukko, P. J., and Houck, M. M. eds.), Academic Press, Waltham. pp 380-385

22. Weyermann, C. (2013) Dating: Document. in Wiley Encyclopedia of Forensic Science (A., J. A. M. ed.), J. Wiley \& Sons (eds.). pp 1-11

23. Koenig, A., and Weyermann, C. (2018) Ink dating part II: Interpretation of results in a legal perspective. Science and Justice 58, 31-46

24. Koenig, A., and Weyermann, C. (2018) Ink dating, part I: Statistical distribution of selected ageing parameters in a ballpoint inks reference population. Science and Justice 58, 17-30

25. e Brito, L. R., Martins, A. R., Braz, A., Chaves, A. B., Braga, J. W., and Pimentel, M. F. (2017) Critical review and trends in forensic investigations of crossing ink lines. TrAC - Trends in Analytical Chemistry 94, 54-69

26. Roux, C., Novotny, M., Evans, I., and Lennard, C. (1999) A study to investigate the evidential value of blue and black ballpoint pen inks in Australia. Forensic Science International 101, 167-176

27. Keipert, C. (2007) The analysis of black pigmented inks by LA-ICP-MS and SEM-EDX. in Department of Chemistry, Materials and Forensic Science, University od Technology, Sydney

28. Bell, S. E. J., Stewart, S. P., Ho, Y. C., Craythorne, B. W., and Speers, S. J. (2013) Comparison of the discriminating power of Raman and surface-enhanced Raman spectroscopy with established techniques for the examination of liquid and gel inks. Journal of Raman Spectroscopy 44, 509-517

29. Techabowornkiat, K., Gaborini, L., and Weyermann, C. (2019) Blue ballpoint pen ink discrimination using filtered light examination and image classification. In preparation

30. Causin, V., Casamassima, R., Marega, C., Maida, P., Schiavone, S., Marigo, A., and Villari, A. (2008) The discrimination potential of ultraviolet-visible spectrophotometry, thin layer chromatography, and Fourier transform infrared spectroscopy for the forensic analysis of black and blue ballpoint inks. Journal of Forensic Sciences 53, 1468-1473 
Chapter 11: Emerging approaches in the analysis of inks on questioned documents

Weyermann Céline, Techabowornkiat Korn-usa, 2019/10/01. dans In: Francese S. (eds) Emerging Technologies for the Analysis of Forensic Traces. Advanced Sciences and Technologies for Security Applications, Springer, Cham.

31. Reed, G., Savage, K., Edwards, D., and Nic Daeid, N. (2014) Hyperspectral imaging of gel pen inks: an emerging tool in document analysis. Sci Justice 54, 71-80

32. Chlebda, D. K., Majda, A., Łojewski, T., and Łojewska, J. (2016) Hyperspectral imaging coupled with chemometric analysis for non-invasive differentiation of black pens. Applied Physics $A$ 122, 957

33. Mazzella, W. D., and Buzzini, P. (2005) Raman spectroscopy of blue gel pen inks. Forensic Science International 152, 241-247

34. Kunicki, M., Fabianśka, E., and Parczewski, A. (2013) Raman spectroscopy supported by optical methods of examination for the purpose of differentiating blue gel pen inks. $Z$ Zagadnien Nauk Sadowych 95, 627-641

35. de Souza Lins Borba, F., Saldanha Honorato, R., and de Juan, A. (2015) Use of Raman spectroscopy and chemometrics to distinguish blue ballpoint pen inks. Forensic Science International 249, 73-82

36. Król, M., Karoly, A., and Kościelniak, P. (2014) Raman spectroscopy and capillary electrophoresis applied to forensic colour inkjet printer inks analysis. Forensic Science International 242, 142-149

37. Zięba-Palus, J., and Kunicki, M. (2006) Application of the micro-FTIR spectroscopy, Raman spectroscopy and XRF method examination of inks. Forensic Science International 158, 164172

38. Andermann, T. (2001) Raman spectroscopy of ink on paper. Problems of Forensic Sciences, 335-344

39. Kunicki, M. (2002) Differentiating blue ballpoint pen inks. Z Zagadnien Nauk Sadowych 51, 56-70

40. Vančo, V., Kadlečíková, M., Breza, J., Michniak, P., reppan, M., Reháková, M., Belányiová, E., and Butvinová, B. (2015) Differentiation of selected blue writing inks by surface-enhanced Raman spectroscopy. Chemical Papers 69, 518-526

41. Kher, A., Mulholland, M., Green, E., and Reedy, B. (2006) Forensic classification of ballpoint pen inks using high performance liquid chromatography and infrared spectroscopy with principal components analysis and linear discriminant analysis. Vibrational Spectroscopy 40, 270-277

42. Udriştioiu, G. E., Bunaciu, A. A., Aboul-Enein, H. Y., and Tănase, G. I. (2009) Infrared Spectrometry in Discriminant Analysis of Laser Printer and Photocopy Toner on Questioned Documents. Instrumentation Science \& Technology 37, 230-240

43. Payne, G., Wallace, C., Reedy, B., Lennard, C., Schuler, R., Exline, D., and Roux, C. (2005) Visible and near-infrared chemical imaging methods for the analysis of selected forensic samples. Talanta 67, 334-344

44. Djozan, D., Baheri, T., Karimian, G., and Shahidi, M. (2008) Forensic discrimination of blue ballpoint pen inks based on thin layer chromatography and image analysis. Forensic Science International 179, 199-205

45. Weyermann, C., Marquis, R., Mazzella, W., and Spengler, B. (2007) Differentiation of blue ballpoint pen inks by laser desorption ionization mass spectrometry and high-performance thin-layer chromatography. Journal of Forensic Sciences 52, 216-220

46. Gallidabino, M., Weyermann, C., and Marquis, R. (2011) Differentiation of blue ballpoint pen inks by positive and negative mode LDI-MS. Forensic Science International 204, 169-178

47. Weyermann, C., Bucher, L., and Majcherczyk, P. (2011) A statistical methodology for the comparison of blue gel pen inks analyzed by laser desorption/ionization mass spectrometry. Science \& Justice 51, 122-130

48. Weyermann, C., Bucher, L., Majcherczyk, P., Mazzella, W., Roux, C., and Esseiva, P. (2012) Statistical discrimination of black gel pen inks analysed by laser desorption/ionization mass spectrometry. Forensic Science International 217, 127-133 
Chapter 11: Emerging approaches in the analysis of inks on questioned documents

Weyermann Céline, Techabowornkiat Korn-usa, 2019/10/01. dans In: Francese S. (eds) Emerging Technologies for the Analysis of Forensic Traces. Advanced Sciences and Technologies for Security Applications, Springer, Cham.

49. Heudt, L., Debois, D., Zimmerman, T. A., Köhler, L., Bano, F., Partouche, F., Duwez, A. S., Gilbert, B., and De Pauw, E. (2012) Raman spectroscopy and laser desorption mass spectrometry for minimal destructive forensic analysis of black and color inkjet printed documents. Forensic Science International 219, 64-75

50. Jones, R. W., and McClelland, J. F. (2013) Analysis of writing inks on paper using direct analysis in real time mass spectrometry. Forensic Science International 231, 73-81

51. Kula, A., Wietecha-Posłuszny, R., Pasionek, K., Król, M., Woźniakiewicz, M., and Kościelniak, P. (2014) Application of laser induced breakdown spectroscopy to examination of writing inks for forensic purposes. Science and Justice 54, 118-125

52. Trejos, T., Flores, A., and Almirall, J. R. (2010) Micro-spectrochemical analysis of document paper and gel inks by laser ablation inductively coupled plasma mass spectrometry and laser induced breakdown spectroscopy. Spectrochimica Acta - Part B Atomic Spectroscopy 65, 884895

53. Trejos, T., Corzo, R., Subedi, K., and Almirall, J. (2014) Characterization of toners and inkjets by laser ablation spectrochemical methods and Scanning Electron Microscopy-Energy Dispersive X-ray Spectroscopy. Spectrochimica Acta - Part B Atomic Spectroscopy 92, 9-22

54. Alamilla, F., Calcerrada, M., García-Ruiz, C., and Torre, M. (2013) Forensic discrimination of blue ballpoint pens on documents by laser ablation inductively coupled plasma mass spectrometry and multivariate analysis. Forensic Science International 228, 1-7

55. Denman, J. A., Skinner, W. M., Kirkbride, K. P., and Kempson, I. M. (2010) Organic and inorganic discrimination of ballpoint pen inks by ToF-SIMS and multivariate statistics. Applied Surface Science 256, 2155-2163

56. Weyermann, C. (2005) Mass Spectrometric Investigation of the Aging Processes of Ballpoint Ink for the Examination of Questioned Documents. PhD Thesis, Faculty of Biology and Chemistry, Justus-Liebig University, Giessen, available on-line: http://geb.unigiessen.de/geb/volltexte/2006/3044/

57. Armitage, S., Saywell, S., Roux, C., Lennard, C., and Greenwood, P. (2001) The Analysis of Forensic Samples Using Laser Micro-Pyrolysis Gas Chromatography Mass Spectrometry,

58. Khan, Z., Shafait, F., and Mian, A. (2015) Automatic ink mismatch detection for forensic document analysis. Pattern Recognition 48, 3615-3626

59. Edelman, G. J., Gaston, E., van Leeuwen, T. G., Cullen, P. J., and Aalders, M. C. G. (2012) Hyperspectral imaging for non-contact analysis of forensic traces. Forensic Science International 223, 28-39

60. Claybourn, M., and Ansell, M. (2000) Using Raman spectroscopy to solve crime: Inks, questioned documents and fraud. Science and Justice - Journal of the Forensic Science Society 40, 261-271

61. White, P. (2000) SERRS Spectroscopy - a new technique for forensic science?,

62. Buzzini, P., Polston, C., and Schackmuth, M. (2018) On the criteria for the discrimination of inkjet printer inks using micro-Raman spectroscopy. Journal of Raman Spectroscopy In press, 1-11

63. Mazzella, W. D., Lennard, C. J., and Margot, P. A. (1991) Classification and identification of photocopying toners by diffuse reflectance infrared Fourier transform spectroscopy (DRIFTS): II. Final report. Journal of Forensic Sciences 36, 820-837

64. Mazzella, W. D., Lennard, C. J., and Margot, P. A. (1991) Classification and identification of photocopying toners by diffuse reflectance infrared Fourier transform spectroscopy (DRIFTS): I. Preliminary results. Journal of Forensic Sciences 36, 449-465

65. Bügler, J., Buchner, H., and Dallmayer, A. (2005) Characterization of Ballpoint Pen Inks by Thermal Desorption and Gas Chromatography-Mass Spectrometry. Journal of forensic Sciences 50, 1209-1214 
Chapter 11: Emerging approaches in the analysis of inks on questioned documents

Weyermann Céline, Techabowornkiat Korn-usa, 2019/10/01. dans In: Francese S. (eds) Emerging Technologies for the Analysis of Forensic Traces. Advanced Sciences and Technologies for Security Applications, Springer, Cham.

66. Otieno-Alego, V. (2009) Some forensic applications of a combined micro-Raman and scanning electron microscopy system. Journal of Raman Spectroscopy 40, 948-953

67. da Silva Oliveira, V., Honorato, R. S., Honorato, F. A., and Pereira, C. F. (2018) Authenticity assessment of banknotes using portable near infrared spectrometer and chemometrics. Forensic Science International 286, 121-127

68. de Araujo, W. R., Cardoso, T. M. G., da Rocha, R. G., Santana, M. H. P., Muñoz, R. A. A., Richter, E. M., Paixão, T. R. L. C., and Coltro, W. K. T. (2018) Portable analytical platforms for forensic chemistry: A review. Analytica Chimica Acta 1034, 1-21

69. Correia, R. M., Domingos, E., Tosato, F., Aquino, L. F. M., Fontes, A. M., Cáo, V. M., Filgueiras, P. R., and Romão, W. (2018) Banknote analysis by portable near infrared spectroscopy. Forensic Chemistry 8, 57-63

70. Teixeira, C. A., and Poppi, R. J. (2019) Discriminating blue ballpoint pens inks in questioned documents by Raman imaging and mean-field approach independent component analysis (MF-ICA). Microchemical Journal 144, 411-418

71. Martins, A., Dourado, C., Alhavini, M., Braz, A., and Braga, J. W. (2018) Determination of chronological order the of crossing lines of ballpoint pens by hyperspectral image in the visible region and multivariate analysis. Forensic Science International Submitted.

72. Silva, C. S., Pimentel, M. F., Honorato, R. S., Pasquini, C., Prats-Montalbán, J. M., and Ferrer, A. (2014) Near infrared hyperspectral imaging for forensic analysis of document forgery. Analyst 139, 5176-5184

73. Lambert, D., Muehlethaler, C., Gueissaz, L., and Massonnet, G. (2014) Raman analysis of multilayer automotive paints in forensic science: measurement variability and depth profile. Journal of Raman Spectroscopy 45, 1285-1292

74. Materazzi, S., Risoluti, R., Pinci, S., and Saverio Romolo, F. (2017) New insights in forensic chemistry: NIR/Chemometrics analysis of toners for questioned documents examination. Talanta 174, 673-678

75. Grim, D. M., Siegel, J. A., and Allison, J. (2001) Evaluation of Desorption/ionization Mass Spectrometric Methods in the Forensic Applications of the Analysis of Inks on Paper. Journal of Forensic Sciences 52, 1411-1420

76. Ifa, D. R., Gumaelius, L. M., Eberlin, L. S., Manicke, N. E., and Cooks, R. G. (2007) Forensic analysis of inks by imaging desorption electrospray ionization (DESI) mass spectrometry. Analyst 132, 461-467

77. Drury, N., Ramotowski, R., and Moini, M. (2018) A comparison between DART-MS and DSAMS in the forensic analysis of writing inks. Forensic Science International 289, 27-32

78. Nguyen, L., and Moini, M. (2016) Direct sample analysis-mass spectrometry vs separation mass spectrometry techniques for the analysis of writing inks. Forensic Chemistry 1, 78-85

79. Trejos, T., Torrione, P., Corzo, R., Raeva, A., Subedi, K., Williamson, R., Yoo, J., and Almirall, J. (2016) A Novel Forensic Tool for the Characterization and Comparison of Printing Ink Evidence: Development and Evaluation of a Searchable Database Using Data Fusion of Spectrochemical Methods. Journal of Forensic Sciences 61, 715-724

80. Braz, A., López-López, M., and García-Ruiz, C. (2014) Studying the variability in the Raman signature of writing pen inks. Forensic Science International 245, 38-44

81. Partouche, F. (2013) Interpol review papers: questioned documents. in 17th Interpol International Forensic Science Managers Symposium (Daéid, N. N. ed., Interpol, Lyon

82. Retailleau, J. (2016) Interpol review papers: questioned documents. in 18th Interpol International Forensic Science Managers Symposium (Houck, M. M. ed., Interpol, Lyon

83. Brunelle, R. L., and Cantu, A. A. (1987) Training Requirements and Ethical Responsabilities of Forensic Scientist Performing Ink Dating Examinations. Journal of Forensic Sciences 32, 15021508 
Chapter 11: Emerging approaches in the analysis of inks on questioned documents

Weyermann Céline, Techabowornkiat Korn-usa, 2019/10/01. dans In: Francese S. (eds) Emerging Technologies for the Analysis of Forensic Traces. Advanced Sciences and Technologies for Security Applications, Springer, Cham.

Octobre 2019 